\title{
Bio-translation of aniline in riverbank filtration under sulfate-reducing conditions
}

\author{
Y. Wu, L. Hui, X. Li, H. Wang \& R. Zeng \\ Department of Applied Chemistry, \\ Northwestern Polytechnical University, People's Republic of China
}

\begin{abstract}
Soil column was equipped with the sediments and aquifer media collected from Weihe Riverbed and its bank, and was used to research the characteristics of aniline degradation in the riverbank filtration under sulfate-reducing conditions. The results show that most aniline could be degraded, even be mineralized by the indigenous microbes under sulfate-reducing conditions, but had a long lag period. The aniline degradation and sulfate reducing produce some intermediates, some of which are harmful to sulfate-reducing microorganisms. In the test process, aniline concentration in infiltrating water was about $33 \mathrm{mg} / \mathrm{L}$, and in leacate increased from 0 to $22.7 \mathrm{mg} / \mathrm{L}$, then dropped and kept at $2 \mathrm{mg} / \mathrm{L}$ or so. Aniline removal rate was $93.94 \%$ and total organic carbon removal rate was $62.13 \%$. One of intermediates is $\mathrm{H}_{2} \mathrm{~S}$ the most harmful to the microorganisms. The lag phase was about 14 days

Keywords: sulfate-reducing conditions, aniline, riverbank filtration, anaerobic bio-translation.
\end{abstract}

\section{Introduction}

Aniline is a liquid organic compound that both toxic and carcinogenic. It is degradable, and its half-life ranges from 5 to 10 days in water under aerobic conditions. However in soil environmental, aniline is degraded noticeably slowly, and its half-life is around 350 days. The same degradation process occurs in soil as in sediments, in an aerobic upper layer of sediments, the half-life is also around 350 days. However, in deep, anaerobic sediments, aniline degradation is much slower and its half-life is approximately 10 years [1]. At present, the annual production of aniline is more than $80000 \mathrm{t}$ in China, and the 
amount of aniline released into the global environment is about 30000t per year [2]. Besides mass production, aniline is also produced nationally by microorganisms from aromatic nitro compounds and aniline based pesticides [3]. Thus, it has been common to detect aniline in surface water and soil $[4,5]$. Since the drinking water was produced from groundwater recharged by surface water through riverbank filtration systems (RBF) widely [6-9], aniline's behavior in $\mathrm{RBF}$ has become an increasing concern.

Anaerobic degradation of organisms usually takes place under nitrate and sulfate reducing conditions. Anaerobic zones, such as denitrifying zones and sulfate reduction zones, always exist in actual RBF systems [8]. Thus, it is possible to degrade organisms anaerobically in a RBF system. Since Schnell et al. [10] and Schnell and Schink 11] discovered sulfate reduction organisms in ocean and river sediments, since it has been confirmed that there are a variety of autochthonous organisms that are able to degrade aniline and river water contaminated by aniline through RBF. Current studies about aniline degradation have been performed under aerobic conditions [12, 13]; yet, few studies have researched the properties of aniline's anaerobic degradation using directly acclimatized autochthonous organisms. This study investigates the Weihe River's RBF. Some media collected from the riverbed sediments and groundwater aquifers along the riverbank were made into soil columns to perform a dynamic soil column experiment. This experiment was used to research aniline's transformation characteristics under sulfate reduction conditions. The purpose of this study is to research the properties of aniline degradation under anaerobic conditions as well as provide a scientific basis for further research of anaerobic wastewater restoration.

\section{Materials and methodology}

\subsection{Riverbed sediments, aquifer media, and chemicals}

Riverbed sediments were collected from riverbed about $500 \mathrm{~m}$ down from Xianyang Bridge on Weihe River, China. Aquifer media, which are mainly comprised of fine and coarse sands, were collected from $2 \mathrm{~m}$ deep at the riverbank. The sediments and media were put into plastic bags respectively and sent to the lab, then put properly into the soil column of the experimental system (Figure 1). The sediments and media were soaked with tap water for more than 6 months to make its state close to the real one, and then the soil column test was carried out.

\subsection{Experimental methodology}

In this study, two types of experimental techniques were used: a static absorption technique and a dynamic technique.

$500 \mathrm{ml}$ triangular flasks with stoppers were reactors for static adsorption test. The ratio of water and soil was $100 \mathrm{ml}: 20 \mathrm{~g}$ in each reactor. The test was conducted at $22^{\circ} \mathrm{C}$ and with vibrating frequency $120 \mathrm{n} / \mathrm{min}$. After a period time, 
samples were taken and settled by a centrifuge, and aniline concentration of the supernatant was analyzed.

Dynamic soil column test was set up as shown in Figure 1. According to the objectives of the test, the tap water, where dissolved oxygen was removed by an ultrasonator, and aniline were mixed up to model river water polluted by aniline. Because $\mathrm{Na}_{2} \mathrm{SO}_{3}$ can react with oxygen and delete dissolved oxygen (DO) of water:

$$
\mathrm{Na}_{2} \mathrm{SO}_{3}+\frac{1}{2} \mathrm{O}_{2} \stackrel{\mathrm{CoCl}_{2}}{\longrightarrow} \mathrm{Na}_{2} \mathrm{SO}_{4}
$$

So during the test process, $\mathrm{Na}_{2} \mathrm{SO}_{3}$ and $\mathrm{CoCl}_{2}$ were added into the model river water, and the water was replaced every 3 days to reduce the effect of oxygen recomplementing. $\mathrm{pH}$ was measured and the concentrations of aniline and sulfate were analyzed for the leakage at specific times. To determine the hydraulic characteristics of the test system under this study conditions, dispersion experiment was conducted with $\mathrm{Cl}^{-}$used as a tracer.

1 Water supply

2 Sediment column (length $30 \mathrm{~cm}$, inner diameter $15 \mathrm{~cm}$ ) 3 Silt sands column (length $50 \mathrm{~cm}$, inner diameter $10 \mathrm{~cm}$ ) 4 Coarse sand column (length $50 \mathrm{~cm}$, inner diameter $10 \mathrm{~cm}$ 5 Leachate bottle

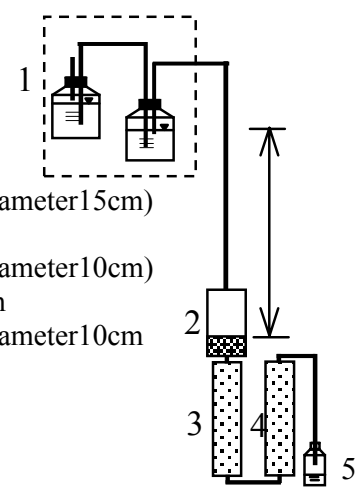

Figure 1: $\quad$ Sketch map of the tester.

\subsection{Analysis methods}

The concentrations of aniline and sulfate as well as $\mathrm{pH}$ and total organic carbon (TOC) in the model river water and leakage, and the contents of organic carbon and nitrogen in the sediments, were measured by national standard methods of China $[20,21]$.

\section{Results and discussion}

\subsection{Basic properties of riverbed sediment}

The contents of organic matter, total nitrogen and ammoniac nitrogen in riverbed sediments were measured by the oil bath heating $-\mathrm{K}_{2} \mathrm{Cr}_{2} \mathrm{O}_{7}$ capacity process, 
Kelvin process and distillation process respectively. The contents of organic carbon and organic nitrogen in dried soil are $47.72 \mathrm{mg} / \mathrm{g}$ and $0.41 \mathrm{mg} / \mathrm{g}$ respectively. The average dry volume weight $(\rho)$ of the sediment and the average degree of porosity (n) were also $1.4794 \mathrm{~g} / \mathrm{cm}^{3}$ and 0.2141 respectively.

\subsection{Absorption equilibrium equation}

From the results of the pretests, static adsorption gets equilibrium in approximately $8 \mathrm{~h}$, when $\mathrm{pH}$ was equal to that in the original water. Then the tests were conducted with 7 model wastewaters with different concentrations of aniline. The equilibration concentrations of aniline in the water (C) and in the soil $(\mathrm{G})$ were determined, and the relation of both was shown in Figure 2.

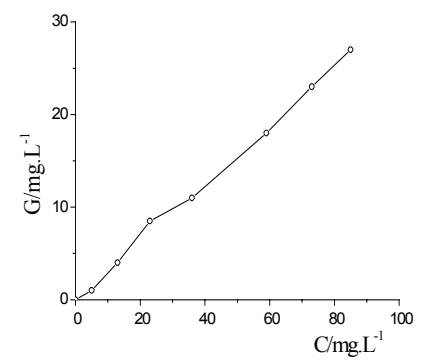

Figure 2: Isotherm curve for aniline adsorption by the sediments.

Figure 2 shows that the adsorption was coincided with linearity rule, described by Henry Model:

$$
\mathrm{G}=\mathrm{K}_{\mathrm{d}} \cdot \mathrm{c}
$$

Here $K_{d}$ is adsorption constant. In this test the adsorption constant $K_{d}$ and the correlation coefficient $(\mathrm{R})$ derived from data by method of least squares was 0.3149 and 0.9979 respectively.

Under the test condition, the lag coefficient $\left(\mathrm{R}_{\mathrm{d}}\right)$ for aniline adsorbed by the sediments was 3.1756, derived from the equation $R_{d}=\left(1+(\rho / n) K_{d}\right.$ [14]. Obviously, $R_{d}$ was far larger than 1 here. Thus, the riverbed sediments had a rather strong adsorption capacity for aniline.

\subsection{Potential electron receptor}

DO was monitored during the test process, and the data shows DO was less than $0.1 \mathrm{mg} / \mathrm{L}$. This shows that the model RBF system is in anaerobic conditions. Other possible electron acceptors in the model river water were also monitored and their concentrations are shown in Table 1. 
Table 1: The concentration for electron acceptors in the system.

\begin{tabular}{ccccc}
\hline electron acceptor & $\mathrm{SO}_{4}{ }^{2-}$ & $\mathrm{DO}$ & $\mathrm{NO}_{3}{ }^{2-}-\mathrm{N}$ & $\mathrm{Fe}^{3+}$ \\
\hline concentration (mg. $\left.\mathrm{L}^{-1}\right)$ & 90 & $<0.1$ & 1.67 & 0.353 \\
\hline
\end{tabular}

From Table 2, it is found that, though there were a variety of electron acceptors in the system, the concentrations of $\mathrm{NO}_{3}{ }^{2-}-\mathrm{N}$ and $\mathrm{Fe}^{3+}$ were $1.67 \mathrm{mg} / \mathrm{L}$ and $0.35 \mathrm{mg} / \mathrm{L}$, even DO was less $0.1 \mathrm{mg} / \mathrm{L}$. Sulfate concentration was far larger than the other. This suggests sulfate is the potentially electron acceptor in the model RBF system.

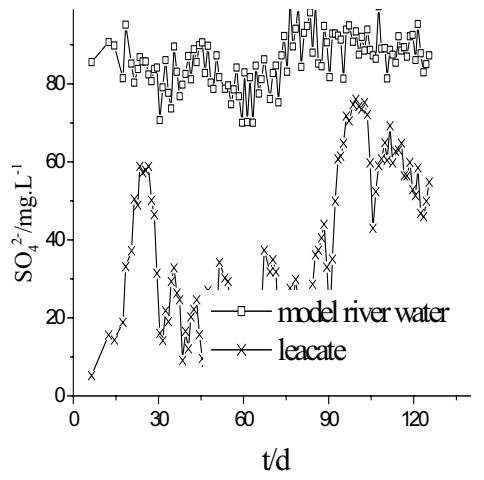

Figure 3: Diachronic curve of $\mathrm{SO}_{4}{ }^{2-}$ Figure 4: concentration in the testing process.

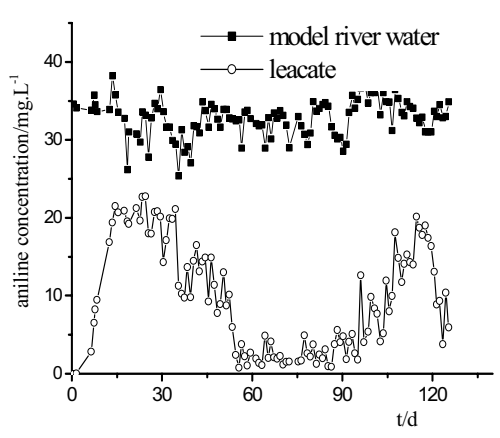

Diachronic curve of aniline concentration in the testing process.

\subsection{Aniline degradation under sulfate-reducing conditions}

Concentrations of aniline and sulfate in leachate from the dynamic experiment are shown in Figures 3 and 4 respectively. During the test process, the aniline's concentration in the leachate went through four phases: (1) increasing from 0 to about $21.6 \mathrm{mg} / \mathrm{L}$, during the first 14 days; (2) kept relatively stable at a high level (around $22 \mathrm{mg} / \mathrm{L}$ ), from the $14^{\text {th }}$ day to the $34^{\text {th }}$ day; (3) decreased from $22 \mathrm{mg} / \mathrm{L}$ to $2 \mathrm{mg} / \mathrm{L}$ from the $34^{\text {th }}$ day to the $55^{\text {th }}$ day; (4) kept relatively stable at a low level (about $2 \mathrm{mg} / \mathrm{L}$ ) since the $55^{\text {th }}$ day. The variation of aniline concentration is completely different from that of conservative pollutant's concentration, when the pollutant is in the same condition where the pollution source is continuous [14]. And the variation of aniline concentration is almost consistent with that of the substrate concentration when microbes grow in batch culture tests. These show aniline was degraded in the model RBF system. Comparing Figures 3 and 4 , the variations of aniline and sulfate concentration are identical, and based on the discussion in 3.3, it is concluded that aniline was degraded in the model RBF system under sulfate-reducing conditions. 


\subsection{Characteristics of aniline bio-transformation in RBF}

\subsubsection{Aniline's degradation has a long lag phase in the RBF}

At the beginning of the experiment, aniline's concentration in leachate from the soil columns was affected by hydrodynamic conditions and physical action between soil and aniline, such as absorption. Therefore, the mass balance equation of aniline can be expressed as $[14,15]$

$$
R_{d} \frac{\partial c}{\partial t}=D \frac{\partial^{2} c}{\partial x^{2}}-v \frac{\partial c}{\partial x}
$$

where, $\mathrm{R}_{\mathrm{d}}$ is the hysteresis coefficient; $\mathrm{x}$ is the abscissa; $\mathrm{D}$ is the hydrodynamic dispersion coefficient and $\mathrm{v}$ is seepage velocity $(\mathrm{m} / \mathrm{h})$. The analytic solution of equation (3) was derived from equation (3) by Laplace Transformation and presented as [16]:

$$
\frac{c}{c_{0}}=\frac{1}{2}\left\{\operatorname{erfc}\left[\frac{R_{d} x-v t}{2 \sqrt{R_{d} D t}}\right]+\exp \left(\frac{v x}{D}\right) \operatorname{erfc}\left[\frac{R_{d} x+v t}{2 \sqrt{R_{d} D t}}\right]\right\}
$$

where, $\operatorname{erfc}[\varphi]$ is a complementary error function. This function is defined as follows:

$$
\operatorname{erfc}[\varphi]=\frac{e^{\left(-\varphi^{2}\right)}}{\pi \cdot \varphi} \cdot\left[1+\sum_{k=1}^{n}(-1)^{n} \cdot \sqrt{\frac{(2 K-1) !}{\left(2 \varphi^{2}\right)^{k}}}\right]
$$

where, $|\arg \varphi| \leq \frac{\pi}{2} \cdot \delta \quad(\delta>0 \quad|\varphi| \rightarrow \infty)$ and $\operatorname{erfc}(\infty)=0$.

The truncation error is :

$$
\left|\gamma_{n}\right| \leq \frac{(2 K-1) !}{\left(2\left|\varphi^{2}\right|\right)^{k-1}} \cdot \sec \delta
$$

According to the data of the dispersion experiment conducted with tracer $\mathrm{Cl}^{-}$as a tracer, based on method suggested by Liu [14], dispersion coefficient and seepage velocity were determined, and were $0.0264 \mathrm{~m}^{2} / \mathrm{d}$ and $0.0363 \mathrm{~m} / \mathrm{d}$ respectively.

The substitution of Equations: $D=0.0264 \mathrm{~m}^{2} / \mathrm{d}, \mathrm{v}=0.0363 \mathrm{~m} / \mathrm{d}$ and $\mathrm{R}_{\mathrm{d}}=3.1756$ into Eq. (4) yields the solution equation to simulate aniline biotransformation in the model RBF, and its simulated curve of aniline is shown in Figure 5.

Aniline's monitored concentration was also shown in Figure 5. Compared the two curves of the simulated and monitored aniline concentrations in Figure 5. It is found that their variations were same within the first 14 days of the test. This indicated that aniline had not become involved in processes and microbes were being acclimatized during this period. However, 14 days later, the monitored concentration of aniline did not increase with time as the simulated one, but decrease. So there was a maximum concentration of aniline. This decrease in aniline concentration may cause from that chemical and (or) biochemical 
reactions where aniline was transformed. According to the test conditions and above discussions, it seems that microbes in the system had been acclimatized to the environment after the 14-day test. So aniline's concentration decrease indicates that acclimatization was achieved.

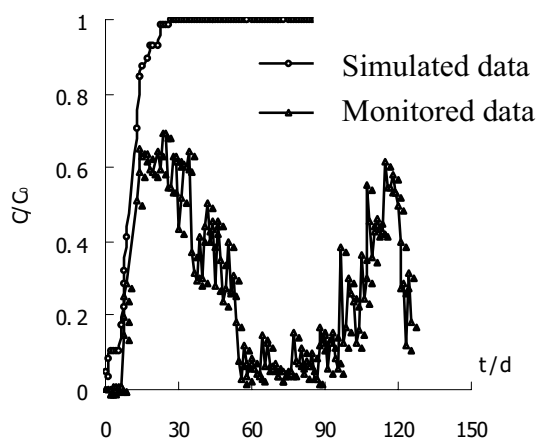

Figure 5: Diachronic curves for monitored and modelled aniline concentration in the testing process

As mentioned in 2.3, sulfate was the main electron acceptor in the system. Sulfate's concentration in leachate decreased while aniline was degraded (Figures 3 and 4). These shows that aniline was degraded under sulfate reducing conditions, and aniline was degraded by microbes, and these microbes may have about a 14-days long lag phase.

Actually, if microorganisms were in the process of acclimatization, the variety and quantity of microorganisms in the system would continuously change. At the same time, the permeation of the model RBF system would also change. The monitored data of the leachate volume shows that the permeation rate changed from about $607 \mathrm{~mL} / \mathrm{d}$ to $1126 \mathrm{~mL} / \mathrm{d}$ near the $14^{\text {th }}$ day of the experiment. This also proves that the microbes were acclimatized and reduced sulfate and degrade aniline since the $14^{\text {th }}$ day.

Though aniline can be degraded in the model RBF under sulfate reducing conditions, must pass a 14-days long lag phase, which is much longer than that under aerobic condition [17]. Therefore, future study should focus on the ways to enhance aniline degradation under sulfate-reducing conditions.

\subsubsection{Aniline degradation, even mineralization}

Aniline's concentration was about $33.50 \mathrm{mg} / \mathrm{L}$ in the model river water, but aniline's maximum concentration in leachate, was merely $22.74 \mathrm{mg} / \mathrm{L}$ and kept stable at about $2 \mathrm{mg} / \mathrm{L}$, as shown in Figure 3 . The decrease in aniline's concentration indicates that aniline was degraded by autochthonous microorganisms. Concentrations of aniline in the model river water and leachate were $33.5 \mathrm{mg} / \mathrm{L}$ and $18.05 \mathrm{mg} / \mathrm{L}$ on 25 th day respectively. The removal rate of aniline was $46.1 \%$ at that time. TOC of the of the model river water and in the 
leachate were also analyzed, and were $28.26 \mathrm{mg} / \mathrm{L}$ and $18.35 \mathrm{mg} / \mathrm{L}$ respectively, thus the removal rate of TOC was $35.1 \%$. The monitoring work was redone on the $70^{\text {th }}$ day, and found the concentrations of aniline in model river water and leachate were $33.76 \mathrm{mg} / \mathrm{L}$ and $2.31 \mathrm{mg} / \mathrm{L}$, TOC in model river water and leachate were $27.83 \mathrm{mg} / \mathrm{L}$ and $10.54 \mathrm{mg} / \mathrm{L}$ respectively. So the removal rates of aniline and TOC were $93.16 \%$ and $62.13 \%$ respectively. These data identified that most of the aniline was not only degraded, but also mineralized by autochthonous microorganisms. However, the removal rate of TOC was far smaller than that of aniline. This shows that it was difficult to degrade aniline completely under the experimental conditions of this study, and meanwhile some byproducts were produced $[11,18,19]$.

\subsubsection{Toxic byproducts were produced}

After the $96^{\text {th }}$ day of the experiment, the concentrations of sulfate (Figure 3 ) and aniline (Figure 4) were increased continuously, and the removal rate of aniline was decreasing. This shows that during aniline degradation process, some byproducts were produced, and some of which influenced aniline's degradation. Remove rates of TOC was smaller that of aniline at same time, this mentions that some by-products were produced from aniline degradation. Meanwhile, some by-products were produced from sulfate-reduce. Some studies proved that sulfate was reduced into sulfide $[11,18,19]$. Some of these by-products may compete with sulfate reduction bacteria for carbon sources, or some of them may affect the activity of sulfate reduction bacteria. Since $94^{\text {th }}$ day of the experiment, biologic velum had broken off in the soil columns, gas had gathered at the top, and the concentrations of aniline and sulfate had increased in the leachate. Those phenomena indicate that sulfate's reduction and aniline degradation were inhibited possibly by the gas gathered at the top. According to the experiment and as well as literature, the gas may mainly comprise of $\mathrm{CO}_{2}$ and $\mathrm{H}_{2} \mathrm{~S}$. When $\mathrm{H}_{2} \mathrm{~S}$ existed in the columns, equilibriums as follows may occur:

1) Equilibrium between gas phase and liquid phase:

$$
H_{2} S_{\text {(liquid })} \Leftrightarrow H_{2} S_{(\text {gas })}
$$

2) Ionization equilibrium in liquid phase:

$$
\begin{aligned}
& H_{2} S_{(\text {liquid })} \Leftrightarrow H S^{-}+H^{+} \quad K_{1}=8.9 \times 10^{-8} \\
& H S^{-} \Leftrightarrow H^{+}+S^{2-} \quad K_{2}=1.3 \times 10^{-15}
\end{aligned}
$$

As shown in Figure 5, $\mathrm{pH}$ in the soil columns was smaller than 8.2. This means, after calculations using some basic chemical theories, that there is little $S^{2-}$ in the solution. Furthermore, $\mathrm{K}_{1}$ is quite small. Thus, the soil columns mostly composed of molecules. $\mathrm{H}_{2} \mathrm{~S}$ is toxic to microorganisms. After the $117^{\text {th }}$ day of the experiment, the gas exhausted from the soil columns had the rotten eggs' odor, which confirms that there was $\mathrm{H}_{2} \mathrm{~S}$ in the system. After the gas was exhausted, the concentrations of aniline and sulfate in the leachate started decreasing. This proves that $\mathrm{H}_{2} \mathrm{~S}$ is toxic to sulfate reduction bacteria under the experimental conditions. Further studies should also detail the effect of the other by-products on the system. 


\section{Conclusion}

(1) Majority of the aniline can be degraded, and even mineralized in the Weihe River's RBF under sulfate reduction conditions. And the degradation was with a about 14-day long lag phase.

(2) Some byproducts were produced from sulfate reduction and aniline degradation. Of them, $\mathrm{H}_{2} \mathrm{~S}$ is the most toxic and can inhibit sulfate reduction and aniline degradation.

\section{Acknowledgement}

This study was supported by the National Natural Science Foundation of China (40472127).

\section{References}

[1] European Commission, Scientific Committee on Toxicity, Ecotoxicity and the Environment (CSTEE), Opinion on the results of the Risk Assessment of: Aniline Environmental part, 2003.

[2] Zhang, J.L., Li, J.W., Chao, F.H. Advance in study on biodegradation of aniline, nitrobenzene and trinitrotoluene. Microbiology, 28(5), pp. 85-88, 2001

[3] Vasili Travkin, Boris P. Baskunov, Eugene L. et al. Reductive deamination as a new step in the anaerobic microbial degradation of halogenated anilines. FEMS Microbiology Letters, 209, pp.307-312, 2002

[4] Lyons CD, Katz S, Bartha R. Mechanisms and pathways of aniline elimination from aquatic environments. Appl. Environ. Microbiol., 48(3), pp.491-496, 1984.

[5] Lacorte, S., M.C. Perrot, D. Fraisse, et al. Determination of chlorobenzidines in industrial effluent by solid-phase extraction and liquid chromatography with electrochemical and mass spectrometric detection. J. Chromatog. A, 833,pp.181-194, 1999

[6] Tufenkji, N., J.N., Ryan and M. Elimelech. The promise of riverbank filtration. Environ. Sci. Technol., 28, pp. 422A-4428A, 2002

[7] Ray C, Grischek T, Schubert J, et al. A perspective of riverbank filtration. J. AWWA, 94 (4), pp. 149-160, 2002

[8] Doussan C., et al, River-bank filtration: Modeling of the changes in water chemistry with emphasis on nitrogen species, J. Contam. Hydrol., 25 (1-2), pp.129-155, 1997

[9] Hiscock, K.M., T. Grischek. Attenuation of groundwater pollution by bank filtration. J. Hydrol., 266, pp. 139-144, 2002.

[10] Schnell S, Bak F, Pfennig N. Anaerobic degradation of aniline and dihydroxybenzenes by newly isolated sulfate-reducing bacteria and description of Desulfobacterium aniline. Arch Microbiol., 52(6), pp. 556-563, 1989 
[11] Schnell, S. and Schink, B. Anaerobic aniline degradation via reductive deamination of 4-aminobenzoyl-CoA in Desulfobacterium aniline. Arch. Microbiol., 155(2), pp. 183-190, 1991.

[12] Murakumi S, Takashima A, Takemoto J, et al. Cloning and sequence analysis of two catechol degrading gene clusters from the anilineassimilating bacterium Frateuria species ANA-18. Gene, 226, pp. 189-198, 1999

[13] Liu Z, H Yang, Z Huang, et al. Degradation of aniline by newly isolated, extremely aniline-tolerant Delftia sp. AN3. Appl. Microbiol. Biotechnol., 58, pp. 679-682, 2002

[14] Liu, Zh.Ch., Zhang L. Sh., Nie, Y.F., et al. Pollution and control of groundwater system, China press house of environmental science, Beijing, pp. 218-219, 1991

[15] Abdul AS et al. Laboratory Studies of the Flow of Some Organic Solvent sand Their Aqueous Solutions Through Bentonite and Kadlin Clays. Ground Water, 28(4), pp. 524-533, 1990

[16] Sim, Y., Chrysikopoulos, C.V. Analytical solutions for solute transport in saturated porous media with semi-infinite or finite thickness. Advances in Water Resources, 22(5), pp. 507-519, 1999

[17] Wang, J.S., Zhao, L.H., Kuang, X., et al. Biodegradation of some aromatic compounds. Acta Scientiae Circumstantiae, 15(4), pp. 407-415, 1995.

[18] Boopathy R. Formation of Aniline as a Transient Metabolite during the Metabolism of Tetryl by a Sulfate-Reducing Bacterial Consortium. Current Microbiology, 40, pp.190-193, 2000

[19] Nico Boon, Johan Goris, Paul De Vos, et al. Genetic Diversity among 3-Chloroaniline- and Aniline-Degrading Strains of the Comamonadaceae. Appl. Environ. Microbiol., 67(3), pp. 1107-1115, 2001

[20] Professional Committee of Agricultural Chemistry, 1983

[21] State Environment Protection Agency, China, 1998 